\title{
Assessment of Prevalence of Exclusive Breast Feeding Practice and Associated Factors among Under Six-Month-Old Children Selected Woreda South Nation Nationality of People Regional State, Ethiopia, 2016
}

\author{
Temesgen Kelaye* \\ Southern Nations Nationalities and Peoples Regional State Bureau of Health Research and Technology supportive core possess, \\ Ethiopia.
}

Received: January 20, 2017; Accepted: September 19, 2017; Published:October 27, 2017

*Corresponding author: Temesgen Kelaye, Southern Nations Nationalities and Peoples Regional State Bureau of Health Research and Technology supportive core possess, Ethiopia, Tel: +251917199604, E-mail: Temesgenkelaye@yahoo.com

\begin{abstract}
Back ground: Exclusive Breast Feeding is feeding the infant only breast milk for six month. EBF practice is observed as a major public health intervention to reduce the child mortality and morbidity. It also, can prevent 1.4 million deaths worldwide among children under five every year. Therefore the main objective of this study was to assess prevalence of exclusive breast feeding practice and associated factors among under sixmonth-old children selected Woreda South Nation Nationality of People Regional State, Ethiopia, 2016.

Methods: A community-based cross sectional study was conducted in Feb 19/ 2016- march 20/2016. A total of 421 mothers were randomly selected. Semi-structured and pretested questionnaires were administered to collect data. One day training was given for data collectors and supervisors. The collected data was entered in to Epi info version7, cleaned and transported to SPSS windows version 20 then analyzed. The crude and adjusted odds ratio (AOR) together with their corresponding 95\% confidence intervals was computed. Bivariate and multivariate logistic regression analysis was computed to identify factors associated EBF. A P-value $<0.05$ were considered to declare a result as statistically significant in this study.

Results: In this study, prevalence of exclusive breast feeding in the study area was $64.8 \%$ [95\% CI: $2.3(61,69.5)]$. The independent predictors of Exclusive breast feeding practice on the multivariate analysis include age of mother, who have age between $26-37$ year's [AOR: 0.592 , 95\% CI: $(0.373,0.938)]$ and age between $38-49$ year [AOR: $0.557,95 \%$ CI: $(0.255,0.989)]$, Availability information of exclusive breast feeding [AOR: 0.432 , 95\% CI: $(0.271,0.687)]$ and had adequate knowledge of mother [AOR: $2.508,95 \%$ CI: $(1.475,4.265)]$ were significantly associated with Exclusive breast feeding practice.

Conclusion: In this study, the prevalence of exclusive breast feeding practice was lower than that of the previous Ethiopian health sector development plan fourth achievement of, 70\%, next five years health sector transformation plan two targeted for, $72 \%$ by the end of 2020 and WHO recommendation, 90\% [10]. But, higher than that of national prevalence of, 52\%, reported in the EDHS. Interventions to promote age of mothers', Availability information during ANC and adequate knowledge about exclusive breast feeding. Recommendations should be include encourage ANC and PNC service utilization, strengthening nutrition counseling during antenatal and postnatal sessions.
\end{abstract}

Keywords: Exclusive breast feeding; SNNPRS; Ethiopia.

\section{Back ground}

Exclusive Breast Feeding (EBF) is feeding the infant only breast milk except for vitamins, minerals, and medications until six month $[1,2]$. EBF is observed as a major public health intervention to reduce the child mortality particularly, in the neonatal and infants [3]. Exclusively breastfeeding can prevent 1.4 million deaths worldwide among children under five every year [4]. The World Health Organization (WHO) and United
Nations Children's Fund (UNICEF) recommend that every infant should be exclusively breastfeed for the first six months of life, with breastfeeding continuing for up to two years of age or longer. This has been trained all over the world as the best cost effective way of feeding the infants, particularly in low-income countries [5-7].

Globally, nearly to, $40 \%$, of infants less than six months of age are exclusively breast feed [8]. Only, 38\%, of infants are 
exclusively breast feeding in the developing countries [9]. EBF Practice is the most effective intervention to save the lives of infants and children. Nearly, $13 \%-15 \%$, of deaths of children aged less than five years could be prevented if universal coverage of EBF were increased to $90 \%$ among infants aged less than six months [10]. A child who is exclusively breastfeed is 14 times less likely to die in the first six months compared to its counterpart while exclusive Breastfeeding highly reduces deaths from the child killer diseases; respiratory infections and diarrhea [11].

In developing countries breastfeeding is a very common practice; however there exist serious obstacles to practicing it until six months from the infant's birth $[12,13]$. Study showed that the prevalence of EBF in Brazil 4\%, Bangladesh 16\%, Rwanda 38\%, Saudi Arabia $8.3 \%$, Congo $2.8 \%$, of infants were exclusively breastfed [14-17]. In Ethiopia the range of prevalence of EBF less than six months were $24.4 \%$ - 81.1\% [19-29]. Currently, the Health Sector Transformation Plan Two (HSPII) has set a target to increase exclusive breastfeeding from 52\% to $72 \%$ in Ethiopia by the end of 2020 [30]. Exclusive breast milk feeding for the first six months of an infant's life is associated with mother knowledge and attitude, age of mother, occupation, family member, Counseling during antenatal and postnatal care, prelacteal feeding, early initiation of breastfeeding, and age of infants, Mothers' income, mode of delivery, place of delivery [2027]. Therefore, this study will review exclusive breast feeding practice and associated factors among under 6-month-old children in selected Woreda South Nation Nationality of People Regional State in Ethiopia.

\section{Methods and Material}

\section{Study Setting and Sample}

Community based cross- sectional study design was conducted from February 3 / 2016 -March 2 /2016 among under six-month-old children in selected Woreda South Nation Nationality of People Regional State, Ethiopia, who had a child less than six month during study period. SNNPRS is the third largest administrative region of Ethiopia. Hawassa is the capital city of the Southern Region, which is $275 \mathrm{kms}$ away from Addis Ababa. Administratively, the state is divided into 14 Zones, one City Administration and 4 special woredas. It represents about $20 \%$ of the country's population. According to 2007 census the regional population was estimated to be 18.9 million. 2007 E.C Ethiopian Final Years Health Bureau report shows that the region has a total of 41 hospitals, 724 health centers and 3,800 health posts [31].

The sample size was determined by using Epi-info version 7 depending on single population proportion formula by the following assumptions. $\mathrm{Z} \alpha / 2$ (95\% confidence interval), prevalence of exclusive breast feeding was 52\% National prevalence of Ethiopia, $\alpha, 0.05$, design effect,1.0, and nonresponse rate, $10 \%$ respectively [32]. Therefore, sample size becomes 383 , having $10 \%$ non-response rate 38 the total sample size become 421 mothers of under six-month-old children.

\section{Data Collection Procedure and Statistical Analysis}

Interviewer administered questionnaire adapted from different literatures and modified according to the local context by the investigators was used to collect data concerning sociodemographics, mother and child characteristics, exclusive breast feeding practices. Furthermore, women's knowledge of most advantageous exclusive breast feeding practices and socio-cultural influences of child feeding were also included in the questionnaire. Their exclusive breastfeeding practices were assessed from their responses. Questionnaire was prepared in English and translated to Amharic by language experts and then back translated to English language by a third person to check the consistency. Also to ensure the data quality it was collected by data collectors who can speak the local and national language and training was given to them. The questionnaires were pre-tested. Based on a pretest result additional adjustment was made.

On site supervision was carried out during the whole period of data collection on daily basis. At the end of each day questionnaires were reviewed and cross checked for completeness, accuracy and consistency by the principal investigator and corrective measures were under taken. The data was entered, coded, and analyzed using SPSS for windows version 20.0. Descriptive statistics such as mean was computed. The findings were presented with tables. Bivariate analysis was performed to identify the association of dependent and independent variables. Odds ratio was computed to see the strength of association between independent and dependent variables. To identify independent predictors, first a bivariate logistic regression was performed at $\mathrm{p}<0.25$ for each independents and outcome of interest. Finally a multivariate logistic regression analysis was made to identify the predictors of exclusive breast feeding practices. Variables which were significant on $p$-values of less than 0.05 were reported as predictors of exclusive breast feeding.

\section{Ethical Consideration}

The study was conducted after getting official permission from an ethical clearance committee of SNNPRSG Regional Health Bureau. Data were collected after getting official permission from Zonal and Woreda health Administration. Letter of cooperation from kebeles administrators was also secured. Informed verbal consent was obtained from each study Participant before data was collected and each respondent was informed about the objective of the study and their right to with draw from the study. Confidentiality was secured.

\section{Results}

\section{Socio-demographic characteristics}

A total of 421 house hold mothers were participated in the study which makes the response rate $100 \%$. The mean age with a standard deviation of the mother was $28.1 \pm 6.1$. Half of respondents', $50.6 \%$, of them belonged to the age group of 2637 years. The majorities, $41.8 \%$, have no formal education and $34.9 \%$, attended primary education. Near, two-thirds, $69.4 \%$, of them belonged to the Christian. More than three-fourth, $76.0 \%$, of them were house wife. The majority, $78.9 \%$, of the occupational 
status were farmer. Nearly, two - thirds, $66.5 \%$, had a monthly income less than seven hundred birr. Nearly, to half of family membered, $47.7 \%$ were interval of four - six family members. All most all 99.0\% mothers were married. Greater than two third, $88.6 \%$, nearly two- third, $72.4 \%$, husband have no other wife and substance use respectively Table 1.

Table 1: Socio-demographic characteristics of mothers with infants aged under six months, selected Woreda Southern, Ethiopia, 2015

\begin{tabular}{|c|c|c|c|}
\hline Characteristics & variable & Frequency & Percent \\
\hline \multirow{3}{*}{ Age of mother } & $15-25$ & 170 & 40.4 \\
\hline & $26-37$ & 213 & 50.6 \\
\hline & $38-49$ & 38 & 9 \\
\hline \multirow{3}{*}{$\begin{array}{l}\text { Education level } \\
\text { of mothers }\end{array}$} & no formal education & 176 & 41.8 \\
\hline & primary & 147 & 34.9 \\
\hline & seconder and above & 99 & 23.3 \\
\hline \multirow{3}{*}{$\begin{array}{l}\text { Religion status } \\
\text { of respondent }\end{array}$} & Christian & 292 & 69.4 \\
\hline & Muslim & 103 & 24.4 \\
\hline & others & 26 & 6.2 \\
\hline \multirow{3}{*}{$\begin{array}{c}\text { Occupation } \\
\text { status of mother }\end{array}$} & Farmer & 66 & 15.7 \\
\hline & House Wife & 320 & 76 \\
\hline & other & 35 & 8.3 \\
\hline \multirow[b]{2}{*}{ Monthly income } & less than 700 birr & 280 & 66.5 \\
\hline & $\begin{array}{c}\text { greater or equal } 700 \\
\text { birr }\end{array}$ & 141 & 33.5 \\
\hline \multirow{3}{*}{ family members } & Less or equal to 3 & 84 & 20 \\
\hline & Between 4-6 & 201 & 47.7 \\
\hline & More or equal 7 & 136 & 32.3 \\
\hline \multirow{2}{*}{ Marital status } & Married & 417 & 99 \\
\hline & single & 4 & 1 \\
\hline \multirow{4}{*}{$\begin{array}{c}\text { Educational } \\
\text { status of husband }\end{array}$} & no formal education & 98 & 23.3 \\
\hline & Primary school & 135 & 32.1 \\
\hline & Secondary school & 83 & 19.7 \\
\hline & Tertiary and above & 105 & 24.9 \\
\hline \multirow{4}{*}{$\begin{array}{c}\text { Occupation } \\
\text { status of husband }\end{array}$} & Farmer & 333 & 78.9 \\
\hline & Governmental & 26 & 6.2 \\
\hline & Merchants & 26 & 6.2 \\
\hline & others & 37 & 8.8 \\
\hline \multirow{2}{*}{$\begin{array}{l}\text { Other wife of } \\
\text { husband }\end{array}$} & yes & 48 & 11.4 \\
\hline & no & 373 & 88.6 \\
\hline \multirow{2}{*}{$\begin{array}{c}\text { Substances use of } \\
\text { husband }\end{array}$} & yes & 116 & 27.6 \\
\hline & no & 307 & 72.4 \\
\hline
\end{tabular}

\begin{tabular}{|c|c|c|c|}
\hline Characteristics & variable & Frequency & Percent \\
\hline \multirow{2}{*}{ Child Sex } & male & 213 & 50.6 \\
\hline & female & 208 & 49.4 \\
\hline \multirow{3}{*}{ Child age } & $\begin{array}{l}\text { less than three } \\
\text { month }\end{array}$ & 144 & 34 \\
\hline & three -four month & 151 & 36 \\
\hline & five -six month & 126 & 30 \\
\hline \multirow{3}{*}{ Birth interval } & $\begin{array}{l}\text { less than two } \\
\text { month }\end{array}$ & 38 & 9 \\
\hline & $\begin{array}{l}\text { greater than two } \\
\text { month }\end{array}$ & 287 & 68.2 \\
\hline & First son & 96 & 22.8 \\
\hline \multirow{3}{*}{$\begin{array}{c}\text { Order of child } \\
\text { birth }\end{array}$} & first birth & 97 & 23 \\
\hline & Two-four & 194 & 46.1 \\
\hline & Fifth and above & 130 & 30.9 \\
\hline \multirow{2}{*}{ GMP } & yes & 66 & 15.7 \\
\hline & no & 355 & 84.3 \\
\hline \multirow{2}{*}{$\begin{array}{c}\text { Child sick past } \\
\text { 2weeks }\end{array}$} & yes & 159 & 37.8 \\
\hline & no & 262 & 62.2 \\
\hline \multirow{6}{*}{$\begin{array}{c}\text { Reason of Child } \\
\text { sick past } 2 \\
\text { weeks (160) }\end{array}$} & diarrhea & 51 & 32 \\
\hline & vomiting & 12 & 7.5 \\
\hline & malaria & 38 & 23.75 \\
\hline & Skin infection & 18 & 11 \\
\hline & eye infection & 9 & 5.75 \\
\hline & other & 32 & $20 \%$ \\
\hline
\end{tabular}

\section{Mothers characteristics}

Majorities of, 83.1\%, mothers visits ANC during pregnant and more than half of, $61 \%$, were visit ANC two -three times. Majorities of, $51.3 \%$, delivers was at the home. Al most all, 99.3\%, of study participants were delivered by vaginally. One- fourth of, $25.7 \%$, mothers visit PNC. Of those visit, $15.9 \%$, were At least once. More than half of mothers, $69.8 \%, 59.4 \%$, were available information 
during on ANC and PNC respectively. Nearly two- third, $72.7 \%$, of respondents have sufficient knowledge. More than two- third, $81.5 \%$, respondents have positive attitude Table 3.

Table 3: Characteristics of mothers with infants age under six months, selected Woreda Southern, Ethiopia, 2015

\begin{tabular}{|c|c|c|c|}
\hline Characteristics & variable & Frequency & Percent \\
\hline \multirow{2}{*}{ ANC visit } & yes & 350 & 83.1 \\
\hline & No & 71 & 16.9 \\
\hline \multirow{3}{*}{$\begin{array}{c}\text { Frequent visit } \\
\text { ANC(353) }\end{array}$} & at least one & 24 & 6.7 \\
\hline & two -three time & 257 & 61 \\
\hline & four or more visit & 136 & 32.3 \\
\hline \multirow{3}{*}{$\begin{array}{l}\text { Please of } \\
\text { delivery }\end{array}$} & home & 216 & 51.3 \\
\hline & hospital & 25 & 5.9 \\
\hline & health institute & 180 & 42.8 \\
\hline \multirow{2}{*}{ Mode of delivery } & caesarean section & 3 & 0.7 \\
\hline & vaginally & 418 & 99.3 \\
\hline \multirow{2}{*}{ PNC visit } & yes & 108 & 25.7 \\
\hline & No & 313 & 74.3 \\
\hline \multirow{3}{*}{$\begin{array}{c}\text { PNC visit } \\
\text { frequency (108) }\end{array}$} & At least one & 67 & 15.9 \\
\hline & two- three & 39 & 9.3 \\
\hline & four or more visit & 2 & 0.5 \\
\hline \multirow{2}{*}{$\begin{array}{c}\text { Available } \\
\text { Information on } \\
\text { ANC EBF }\end{array}$} & yes & 294 & 69.8 \\
\hline & no & 127 & 30.2 \\
\hline \multirow{2}{*}{$\begin{array}{c}\text { Available } \\
\text { Information on } \\
\text { PNC EBF }\end{array}$} & yes & 250 & 59.4 \\
\hline & no & 171 & 40.6 \\
\hline \multirow{2}{*}{$\begin{array}{c}\text { Have sufficient } \\
\text { knowledge }\end{array}$} & Have knowledge & 306 & 72.7 \\
\hline & $\begin{array}{c}\text { Have no sufficient } \\
\text { knowledge }\end{array}$ & 115 & 27.3 \\
\hline \multirow{2}{*}{ Attitude } & Positive attitude & 343 & 81.5 \\
\hline & Negative attitude & 78 & 18.5 \\
\hline
\end{tabular}

\section{Breast feeding practice}

In this study almost all study participants had initiated ever breast feeding. $97.4 \%$, of study participant initiated ever breast feeding. More than two- third of, 78\%, study participant breast feed within one hour. More than three-fourth of, 84\%, study participant were given first three day colostrum's given. Only, $4.8 \%$, study participant were given additional liquid after birth three day. Almost all of, 94.5\%, mother breastfeed with twenty four after delivery. But only, 4.5\%, mother did not breast feed after deliver with in twenty four hours. More than half of, $62.5 \%$, study participant breast feed more than eight times within twenty four hours. Only, 10.0\% were given bottle feeding. Prevalence of exclusive breast feeding during the study period was $64.8 \%$ [95\% CI: $2.3\{60.5,69.6)]$. Nearly two third, $72.7 \%$, of study participant were completely satisfied with infant feeding Table 4.
Table 4: Breast feeding characteristics of mothers with infants age under six months, selected Woreda Southern, Ethiopia, 2015

\begin{tabular}{|c|c|c|c|}
\hline Characteristics & variable & Frequency & Percent \\
\hline \multirow{2}{*}{$\begin{array}{c}\text { Ever Breast feed } \\
\text { child }\end{array}$} & yes & 410 & 97.4 \\
\hline & no & 11 & 2.6 \\
\hline \multirow{2}{*}{$\begin{array}{c}\text { Time interval of } \\
\text { breast feeding after } \\
\text { birth }\end{array}$} & Within one hours & 93 & 22 \\
\hline & After one hours & 328 & 78 \\
\hline \multirow{2}{*}{$\begin{array}{l}\text { First three day } \\
\text { colostrum's given }\end{array}$} & yes & 353 & 84 \\
\hline & no & 68 & 16 \\
\hline \multirow{2}{*}{$\begin{array}{l}\text { After birth three day } \\
\text { given liquid }\end{array}$} & yes & 20 & 4.8 \\
\hline & no & 401 & 95.2 \\
\hline \multirow{2}{*}{$\begin{array}{c}\text { Breasted feed within } \\
24 \mathrm{~h}\end{array}$} & yes & 402 & 94.5 \\
\hline & no & 19 & 4.5 \\
\hline \multirow{2}{*}{$\begin{array}{l}\text { Frequents of Bf with } \\
\qquad 24 \mathrm{~h}\end{array}$} & less than 8 times & 158 & 37.5 \\
\hline & $\begin{array}{l}\text { More than } 8 \\
\text { times }\end{array}$ & 263 & 62.5 \\
\hline \multirow{2}{*}{$\begin{array}{l}\text { Exclusive breast } \\
\text { feeding }\end{array}$} & no & 148 & 35.2 \\
\hline & yes & 273 & 64.8 \\
\hline \multirow{2}{*}{ Bottle feeding } & yes & 42 & 10 \\
\hline & no & 379 & 90 \\
\hline \multirow{2}{*}{$\begin{array}{c}\text { Yesterday other } \\
\text { than breast milk at } \\
\text { food }\end{array}$} & yes & 366 & 87 \\
\hline & no & 55 & 13 \\
\hline \multirow{2}{*}{$\begin{array}{c}\text { Special type of } \\
\text { feeding during child } \\
\text { illness }\end{array}$} & yes & 36 & 8.5 \\
\hline & no & 385 & 91.5 \\
\hline \multirow{5}{*}{$\begin{array}{l}\text { Satisfied with infant } \\
\text { feeding practice }\end{array}$} & $\begin{array}{c}\text { completely } \\
\text { satisfied }\end{array}$ & 306 & 72.7 \\
\hline & partially satisfied & 94 & 22.3 \\
\hline & $\begin{array}{l}\text { initially satisfied } \\
\text { but now }\end{array}$ & 9 & 2.1 \\
\hline & $\begin{array}{c}\text { now am } \\
\text { satisfied but not } \\
\text { previously }\end{array}$ & 6 & 1.4 \\
\hline & not satisfied & 6 & 1.4 \\
\hline \multirow{2}{*}{ Early imitation } & no & 114 & 27 \\
\hline & yes & 307 & 73 \\
\hline
\end{tabular}




\section{Factors associated with exclusive breast feeding}

Hosmer- Lemeshow goodness of fit test was used to assess the fitness of model. Listed Factor which remained statistically significant in the bivariate and multivariate logistic regression analyses. During the bivariate logistics regression analysis, age of mother, Information of exclusive breast feeding during ANC/ PNC, Place of delivery, attitude of mother, adequate knowledge of mother and immediate the birth given liquid were significantly associated with Exclusive breast feeding practice. During the Multivariate logistic regression analysis, age of mother, Availability Information on exclusive breast feeding during ANC and adequate knowledge of mother were significantly associated with exclusive breast feeding. But, Place of delivery, attitude of mother, and immediate the birth given liquid was not associated with exclusive breast feeding.

In this study, the independent predictors of Exclusive breast feeding practice on the multivariate analysis include age of mother, who have age between 26- 37 year's [AOR: 0.592, 95\% CI: $(0.373,0.938)]$ and age between 38-49 year [AOR: 0.557, 95\%CI: $(0.255,0.989)]$, Availability information of exclusive breast feeding during ANC [AOR: 0.432, 95\% CI: $(0.271,0.687)]$ and adequate knowledge of mother [AOR: 2.508, 95\% CI: $(1.475,4.265)]$ Table 5.

Table 5: Bivariate and multivariate analysis for factors associated with EBFP among mothers with infant's age under six months, selected Woreda Southern, Ethiopia, 2015

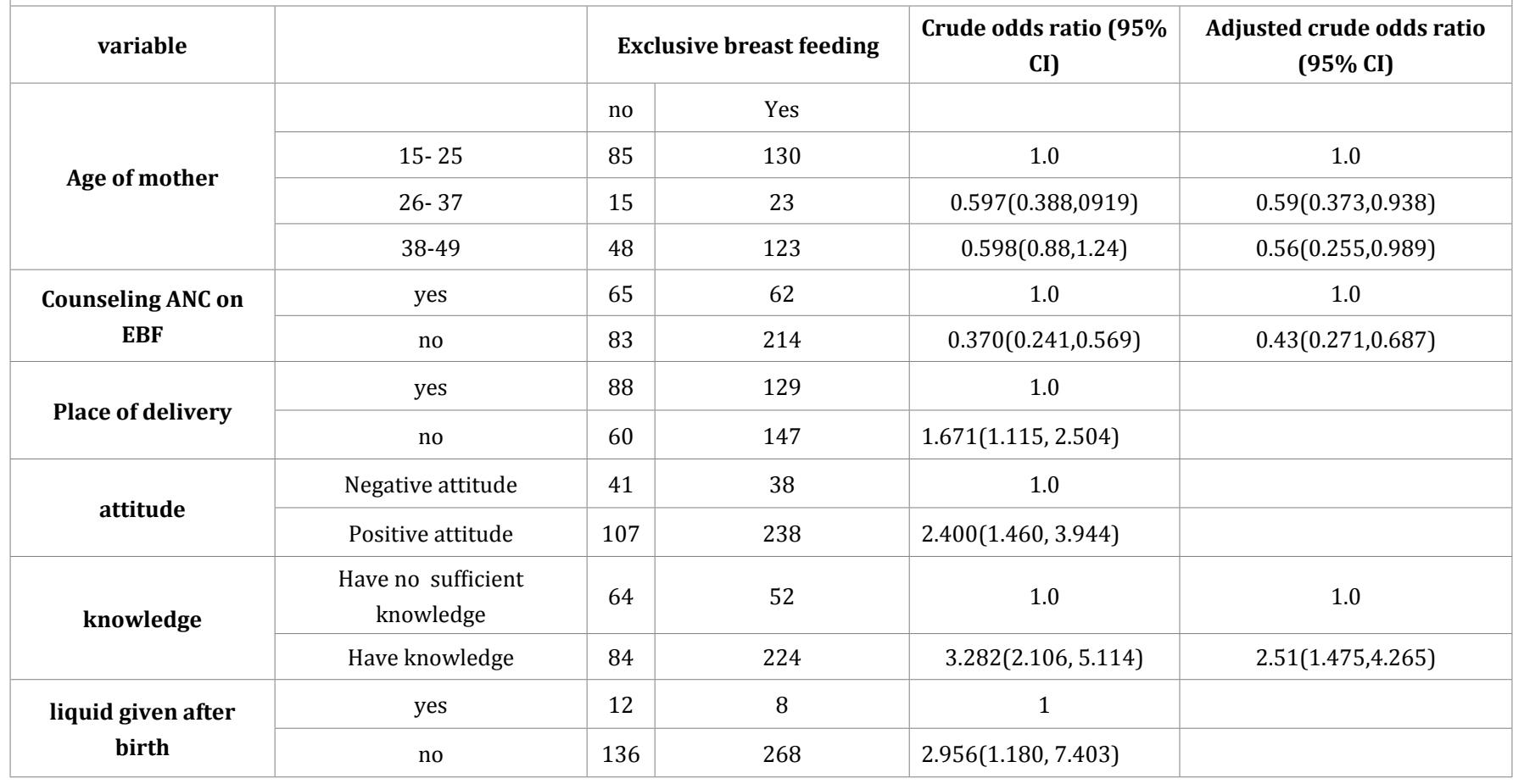

\section{Definition of variables}

-Age of mother: The mothers who has breast feeding age between $15 y e a r s$ up49 years during data collection period.

-Counseling ANC about exclusive breast feeding: Mother who has visiting health institution or health post during antenatal care who has counseled about exclusive breast feeding.

-Place of delivery: Mothers delivered only in health institution or hospitals.

-Positive attitude about exclusive breast feeding: When the mothers agree and strongly agree to auspicious question to exclusive breast feeding.

-Negative attitude about exclusive breast feeding: When the mothers neutral, disagree and strongly disagree to auspicious question to exclusive breast feeding.
-Have no sufficient knowledge: When the mothers correctly answer blow $52 \%$ of questions about exclusive breast feeding.

-Have sufficient knowledge: When the mothers correctly answer equal to $52 \%$ or above $52 \%$ of questions about exclusive breast feeding.

-Liquid given after birth: Mother who gives any liquid (water, milk or milk products...etc.) after the birth.

-Exclusive breast feeding: Infants who have received only breast milk from his/her mother for six month without any other liquid or solids with exception of vitamins, minerals or medication. 


\section{Discussion}

In this study, the prevalence of Exclusive breast feeding practice was, $64.8 \%$, which is lower than that of the previous Ethiopian health Sector Development plan fourth, $70 \%\{33\}$, next five years Health Sector transformation plan two targeted for, $72 \%$ by the end of 2020 and WHO recommendation, $90 \%$ $[10,30]$. But, this finding was higher than that of the national prevalence, $52 \%\{32\}$. The prevalence of exclusive breast feeding in this study higher than that of reported in previous study in Brazil, 4\%, Bangladesh, 16\%, Saudi Arabia, 8.3\%, Rwanda, 38\%, Congo, 2.8\%, Malaysia, 43.1\%, Nigeria ,16.4\%, Meerut, 34.8\% [13-17,33,35]. In Ethiopia reported low prevalence in Mizan Aman town, $26.4 \%$, Addis Ababa ,29.3 \%, North Gondar, 35.9\%, Southern Ethiopia, 48.2\%, Arba Minch Zuria, 55.6\% , Gedeo , 57.6 $\%$, Debre Markos, $60.8 \%$, District of Debre Markos town and Gozamen, 55\% and 64\% respectively[19-26]. Higher prevalence reported in Debre Berhan, 68.6 \%, Goba district, south east, 71.3\%, and Dubti town, afar region, and $81.1 \%$ respectively [27,30,34]. The difference could be due to in sample size, and method of data collection, Socio-demographic factors, environmental condition, human Cultural Behaviors, awareness of mother, commitments of community health extension worker.

One important finding of this study was the identification of independent predictors influencing Exclusive breast feeding. It was found that young mothers' (15-25 years old) were 0.41 times, 0.44 times more likely to practice exclusive breastfeed than age between 26-37 and 38-49 years old respectively. This is similar in Debre Markos town and Gozamen District [26]. The possible explanation could be due to health extension promotion availability on exclusive breast feeding practice, strong linkage health center with community health extension worker. Also, this study was inline agreement with studies in Gedeo [24]. That means it showed a more chance of exclusive breastfeeding in young mother age. A reason might be younger mothers makes them sensitive to exclusive breastfeeding.

Infant feeding counseling during ANC is one of child health service factor that has a significant association with EBF. Those mothers who received counseling concerning infant feeding during ANC were 0.57 times more likely to feed breast milk only for their infants than those not counseled. This is in line with a study from Addis Ababa and Debre Markos where the odds of EBF was higher among infants of mothers who received breastfeeding counseling during ANC follow up compared to those who doesn't received breastfeeding counseling during ANC Follow up [20,25]. This finding was in line with those studies conducted Injibara and Arbaminch $[34,35]$. This confirmations is clarified that antenatal period is an exact time to provide breastfeeding counseling. The possible explanation may be expansion of antenatal care services, 1 to 5 mothers' network awareness, and voluntary community health promotion and community health extension program may increase antenatal care service.

One of important independent outcome variable of factor that was shown to have a significant association with EBF is mothers' breastfeeding knowledge. Mothers who had adequate knowledge about exclusively breastfeeding were 2.51 times more likely to exclusively breastfeed their infants than those who didn't have adequate knowledge about breastfeeding. This has similarities with study findings from Debre Markos [25]. This effect could be partly explained by mother's enhanced knowledge of the welfares of breastfeeding for themselves and their infants, improving the likelihood mothers will breastfeed their infants even if alternatives are available. Also, this outcome could be of community based and health promotion and level of mother education.

\section{Conclusion}

In this study a relatively higher prevalence of exclusive breastfeeding practice rate was observed compared to the national prevalence of the EDHS and other similarly studies in developing countries. However, this does not mean that there will be no need for further strengthening the exclusive breast feeding practice programs. Interventions should promote focus on areas, such as age of mothers', Availability information during ANC and adequate knowledge about exclusive breastfeeding. Recommendations should be include encourage ANC and PNC service utilization, strengthening nutrition counseling during antenatal and postnatal sessions.

\section{Authors' contributions}

Temesgen Kelaye contributed to all research activities such as design of the study performed the statistical analysis and drafting the manuscript and approved the final manuscript.

\section{Acknowledgments}

The authors would like to acknowledge Southern Nations Nationalities and Peoples Regional State Bureau of Health for logistic support. Finally would like to thanks data collectors, mothers who participated in this study.

\section{References}

1. World Health Organization. Indicators for assessing infant and young child feeding practice part 3. WHO;Geneva:2010.

2. Kramer MS, Kaluma R. The optimal duration of exclusive breastfeeding: A systematic review.WHO.

3. Adil Ali N. knowledge, attitude and practice regarding exclusive breastfeeding among mothers attending primary health care centers in Abha city. Int J Med Sci Public Health. 2014;3(11):1355-1363.

4. United Nations Children's Fund. Improving Exclusive Breast Feeding Practices by using Communication for Development in Infant and young Child Feeding Programs. United Nations Children's Fund;2010.

5. USAID. Efforts to prevent mother to child transmission of HIV/AIDS. An overview of U.S. Agency for international development programs and approaches. Washington D.C. 2001.

6. WHO. Effect of breastfeeding on infant and child mortality due to infectious diseases in less developed countries: a pooled analysis. WHO Collaborative study team on the role of breastfeeding on the prevention of infant mortality. Lancet. 2000;355(9202):451-455.

7. UNICEF. United for children against AIDS. UNICEF HIV/AIDS programs in Malawi, 2008. 
8. Ten facts on breast feeding, World Health Organization, July 2012.

9. Breast feeding: impact on child survival and global situation, United Nations Children's Fund, January 2005.

10. Doherty T, Sanders D, Goga A, Jackson D. Implications of the new WHO guidelines on HIV and infant feeding for child survival in South Africa. Bulletin of the World Health Organization. 2011;89:62-67. doi: 10.2471/BLT.10.079798

11.UNICEF. Nutrition-breastfeeding. Unite for children. Update: 6 November 2013.

12. Petrova A, Ayers C, Stechna S, Gerling JA, Mehta R. Effectiveness of exclusive Breastfeeding Promotion in Low-Income Mothers: A Randomized Controlled Study. Breastfeed Med. 2009;4(2):63-69. doi: $10.1089 / \mathrm{bfm} .2008 .0126$

13. Alemayehu T, Haidar J and Habte D. Determinants of exclusive breastfeeding practices in Ethiopia. Ethiop.J.Health Dev. 2009;23(1):118.

14. Singh B. Knowledge, Attitude and Practice of Breastfeeding - A Case Study. Euro. J. Scientific Research. 2010;40(3):404-422.

15. Mihrshahi S, Ichikawa N, Shuaib M, Oddy W, Ampon R, Dibley MJ, et al. Prevalence of exclusive breastfeeding in Bangladesh and its association with diarrhoea and acute respiratory infection: results of the multiple indicator cluster survey 2003. J Health Popul Nutr. 2007;25(2):195204.

16. National Institute of Statistics of Rwanda / Food World Programme/ United Nations Children's Fund \& World Relief. Rwanda Comprehensive Food Security and Vulnerability Analysis and Nutrition Survey. 2009.

17.Al-Binali A M. Breastfeeding knowledge, attitude and practice among school teachers in Abha female educational district, southwestern Saudi Arabia. Int Breastfeed J. 2012;7(1):10. doi: 10.1186/17464358-7-10

18. Babakazo P, Donnen P, Akilimali P, Mala-Ali NM, Okitolonda E. Predictors of discontinuing exclusive breastfeeding before six months among mothers in Kinshasa:a prospective study. Int Breastfeed J. 2015;10:19. doi: 10.1186/s13006-015-0044-7

19. Tadele N, Habta F, Akmel D and Deges E. Knowledge, attitude and practice towards exclusive breastfeeding among lactating mothers in Mizan Aman town, Southwestern Ethiopia: descriptive cross-sectional study. Int Breastfeed J. 2016;11:3. doi: 10.1186/s13006-016-0062-0

20.Shifraw T, Worku A, Berhane Y. Factors associated with exclusive breastfeeding practices of urban women in Addis Ababa public health centers, Ethiopia: a cross sectional study. Int Breastfeed J. 2015;10:22.

21. Assefa B, Boru B. Breastfeeding practice and associated factors among female nurses and midwives at North Gondar Zone, Northwest Ethiopia: a cross sectional institution based study. Int Breastfeed J. 2014;9:11. doi: 10.1186/1746-4358-9-11

22. Eshetu K, Wakgari N. Attitude and practice towards exclusive breastfeeding and its associated factors among HIV positive mothers in southern Ethiopia. Am J Health Res. 2015;3(2):105-115.
23. Tamiru D, Mohammed S. Maternal knowledge of optimal breastfeeding practices and associated factors in rural communities of Arba minchZuriya. Int J Nutr Food Sci. 2013;2(3):122-129.

24. Reddy S and Abuka T. Determinants of Exclusive Breastfeeding Practice among Mothers of Children Under Two Years Old In Dilla Zuria District, Gedeo Zone, Snnpr, Ethiopia, 2014. J Preg Child Health. 2016;3:224. doi:10.4172/2376-127X.1000224

25. Mekuria G and Edris M. Exclusive breastfeeding and associated factors among mothers in Debre Markos, Northwest Ethiopia: a crosssectional study. Int Breastfeed J. 2015;10(1):1. doi: 10.1186/s13006014-0027-0

26. Sinshaw Y, Ketema K and Tesfa M. Exclusive Breast Feeding Practice and Associated Factors Among Mothers in Debre Markos Town and Gozamen District, East Gojjam Zone, North West Ethiopia. Journal of Food and Nutrition Sciences. 2015;3(5):174-179 .

27. Mitiku M, Damte M, Kebede Z. Factors associated with exclusive breastfeeding practices in Debre Berhan District, Central Ethiopia: a cross sectional community based study. Int Breastfeed J. 2015;10:23.

28. Tesfaye Setegn, Tefera Belachew, Mulusew Gerbaba, Kebede Deribe, Amare Deribew, Sibhatu Biadgilign. Factors associated with exclusive breastfeeding practices among mothers in Goba district, south east Ethiopia: a cross-sectional study. International breast feeding journal. 2012;7:17.

29. Liben ML, Gemechu YB, Adugnew M, Asrade A, Adamie B, Gebremedin E, et al.. Factors associated with exclusive breastfeeding practices among mothers in Dubti town, afar regional state, northeast Ethiopia: a community based cross sectional study. Int Breastfeed J. 2016;11:4. doi: 10.1186/s13006-016-0064-y

30. Federal Democratic Republic of Ethiopia Ministry of Health, Health Sector Transformation Plan Two, 2015/2016- 2019/20, Addis Ababa Ethiopia.

31. South Nation Nationality of people of Ethiopia Health Bureau. Annual EFY report of SNNPR Health Bureau. 2007; Ethiopia.

32. Central Statistical Agency [Ethiopia] and ICF International. Ethiopia demographic and health survey 2011. Addis Ababa: Central Statistical Agency and ICF International. 2012.

33. Federal Democratic Republic of Ethiopia Ministry of Health. Health Sector Development Program IV 2010/11-2014/15. Federal Democratic Republic of Ethiopia Ministry of Health. 2010;Addis Ababa.

34. Mathewos E. Exclusive breastfeeding in Arbaminch, SNNPR, Ethiopia. Harar Bulletin of Health Sciences. Extract Number 5, June 2012.

35.Mekuanint T, Lakew A, Netsanet F. Exclusive Breastfeeding and Maternal Employment in Ethiopia: A Comparative Cross- Sectional Study. International Journal of Nutrition and Food Sciences. 2014;3(6):497-503. doi: 10.11648/j.ijnfs.20140306.12 